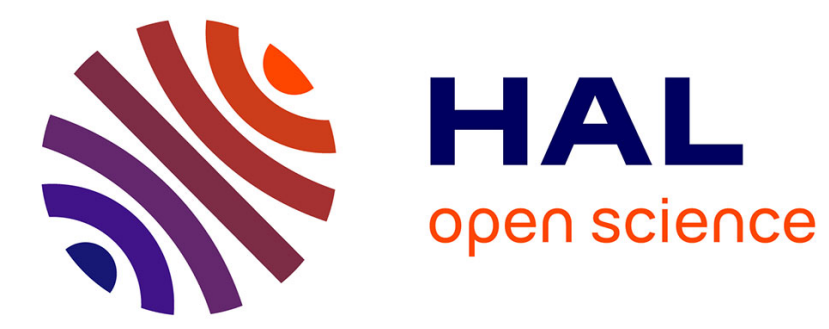

\title{
Coordinating Public E-services - Investigating Mechanisms and Practices in a Government Agency
}

Fredrik Söderström, Ulf Melin, Ida Lindgren, Zara Galzie

\section{To cite this version:}

Fredrik Söderström, Ulf Melin, Ida Lindgren, Zara Galzie. Coordinating Public E-services - Investigating Mechanisms and Practices in a Government Agency. 17th International Conference on Electronic Government (EGOV), Sep 2018, Krems, Austria. pp.85-97, 10.1007/978-3-319-98690-6_8 . hal01961524

\section{HAL Id: hal-01961524 \\ https://hal.inria.fr/hal-01961524}

Submitted on 20 Dec 2018

HAL is a multi-disciplinary open access archive for the deposit and dissemination of scientific research documents, whether they are published or not. The documents may come from teaching and research institutions in France or abroad, or from public or private research centers.
L'archive ouverte pluridisciplinaire HAL, est destinée au dépôt et à la diffusion de documents scientifiques de niveau recherche, publiés ou non, émanant des établissements d'enseignement et de recherche français ou étrangers, des laboratoires publics ou privés. 


\title{
Coordinating public e-services - investigating mechanisms and practices in a government agency
}

\author{
Fredrik Söderström ${ }^{1[0000-0002-2422-0900]}$, Ulf Melin ${ }^{10000-0002-2784-863 X]}$, \\ Ida Lindgren ${ }^{10000-0002-4735-8697]}$ and Zara Galzie ${ }^{1}$ \\ ${ }^{1}$ Linköping University, SE-581 83 Linköping, Sweden \\ \{fredrik.soderstrom, ulf.melin, ida.lindgren, zara.galzie\} \\ aliu.se
}

\begin{abstract}
Coordination is a critical enabler when creating and managing coherent, integrated, secure and smart public electronic services (e-services) as a part of digitalization. With an increased demand for such services, coordination as an internal organizational phenomenon is becoming increasingly important. Based on a qualitative case study, and informed by coordination theory, this paper investigates two different theoretical views applied on internal e-service coordination within a government agency in Sweden. At the outset, the agency is seeking one generic way to coordinate the current heterogeneous and fragmented internal e-service landscape in a more efficient way. Hence, our aim also includes investigating the prerequisites and potential for this type of coordination. We conduct this study in two stages. First, we apply a well-established theoretical lens from organizational theory on a set of coordination efforts, thereby perceiving coordination as a planned and anticipated activity based on a fixed set of mechanisms. Second, we apply a lens of coordinating as emergent practice, which allows for an in-depth investigation of more flexible and dynamic aspects of coordinating activities in daily work. By combining these two views, we argue that this approach can facilitate and increase understanding of the dynamics and flexibility needed to understand the type of coordination needed in public e-service contexts. This can also imply that there is no single best practice or 'one-size-fitsall' approach to internal e-service coordination. Instead, organizations need to acknowledge the need for multi-dimensional views revealing the inherent complexity of coordination; as planned as well as emerging activities.
\end{abstract}

Keywords: Coordination, Coordination Mechanisms, E-government, E-services, Digital Services, Public Sector ICT, Public Sector Digitalization.

\section{Introduction}

This paper elaborates on the formal mechanisms and emerging practices of coordination of electronic services (e-services) in a government agency. Coordinating activities are recognized as vital parts of organizing and refer to the actions taken by humans in organizations or other social settings to generate anticipated and appropriate outcomes: "To organize is to assemble ongoing interdependent actions into sensible sequences 
that generate sensible outcomes." $[1$, p. 3]. Coordination is an essential subset of organizing with fundamental characteristics of formalizing actions and reducing undesired variation by increased control and the ability to anticipate actions [2-4]. Coordination also minimizes the risk of overlapping and even conflicting actions among stakeholders [5]. Organizational relationships enacted via informal, dynamic activities need to be aligned [6] in turn creating a tension between anticipated and spontaneous activities of coordination; described as the organizational paradox [4, 7]. Achieving a balance between reductions of variation and the need for flexibility therefore becomes critical. Transdisciplinary coordination studies describe organizational actions as mutually dependent hence, balanced handling is required $[4,8]$. Acknowledging this need for balance, we use different streams of coordination theory as our basis for formulating two different theoretical lenses; viewing coordination as formal mechanisms [e.g. 3] and coordinating as emerging practices [e.g. 6].

In a public e-service context, we agree with researchers putting forth the need for fixed as well as emergent views of coordination, i.e. formal mechanisms and informal practices [e.g. 6]. As artefacts, e-services are intertwined with policies and practices of coordinating such services $[8,9]$. This creates a need to investigate and understand the characteristics, complexity and coordination of public e-services, in policy, as formal mechanisms, as well as in emergent practice. Benefits and expectations such as increased internal efficiency and external availability [e.g. 10,11] make the ability to provide e-services a necessity for a majority of public organizations. Due to Sweden's governance model, citizens communicate with several government agencies on a regular basis. However, due to public organizations' independence, the level of digitalization, e.g. regarding e-services, varies considerably across the public sector. As exemplified by the case study, complexity and fragmentation are significant challenges to be handled in a digitalization context, and these challenges can also be related to coordination efforts [12].

Investigating e-service coordination challenges is thereby still of importance to government digitalization practice, as well as e-government research. This paper highlights different shapes and roles of coordination in an e-service context by investigating its formal and informal dimensions and expressions. This paper addresses the following research questions (RQ): 1) How are e-services coordinated in a public agency? 2) How can this coordination be described using two different theoretical lenses of coordination? 3) What can we learn from combining these lenses to develop a more dynamic and flexible view of e-service coordination? To address these questions, we must first investigate how e-services are coordinated at the agency (RQ1), then review how the two different theoretical lenses can be applied (RQ2) and finally, how these lenses can be combined and applied for interesting insights (RQ3). Therefore, the aim of this paper is to present an approach in which formal as well as informal acts of coordination are taken into consideration. This paper is organized as follows; the second section covers related research such as coordination as mechanisms, coordinating as practice and e-service coordination. In the third section, the research approach and case study are presented. The analysis and findings are outlined in the fourth section followed by a discussion in section five. The paper is concluded with some concluding remarks and suggestions for future research. 


\section{Related research}

\subsection{Coordination as mechanisms}

As introduced above, well-known views on coordination and related mechanisms are presented by scholars such as March and Simon [2] and Mintzberg [3]; Mintzberg [13]. Three activities are described as central: coordination through standardization, coordination through planning, and coordination through feedback [2]. Similarly, Van de Ven et al. [14] describe three predominant modes of coordination as impersonal by plans or programming, personal by mutual adjustments or feedback and group-based by unscheduled or scheduled activities. Partly based on March and Simon [2], Mintzberg develops the following set of coordination mechanisms: (1) mutual adjustment, (2) direct supervision, (3) standardization of skills and norms, (4) work processes, and (5) results $[3,13]$.

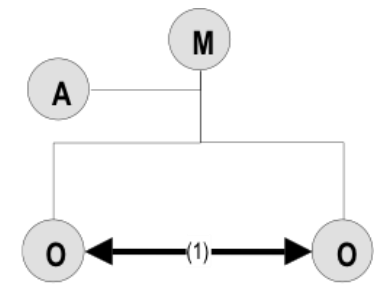

Mutual adjustment

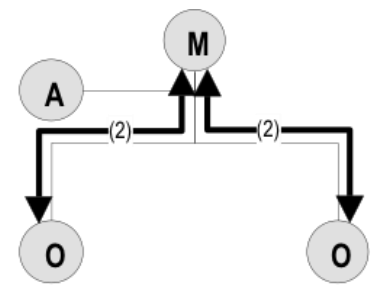

Direct supervision

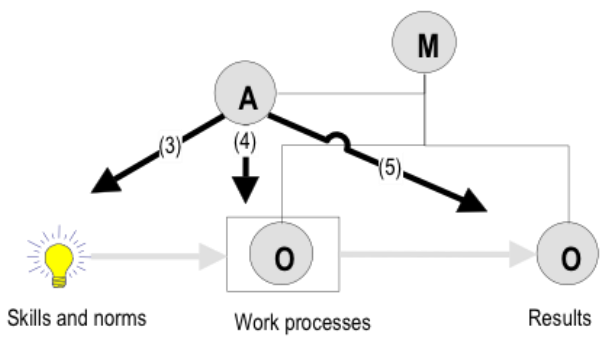

Standardization

Fig. 1. Coordination mechanisms [3 revised by Melin \& Axelsson 2005]

Mutual adjustment (1) achieves coordination of activities by the process of informal coordination. The control of the activities rests mostly in "the hands of the doers" on an operative level ("O" in Figure 1). Direct supervision (2) expresses a more hierarchical model where coordination is achieved by assigning one actor to a role responsible for the work of others ("M" in Figure 1). In this role, managers typically issue instructions to actors on the operative level thus monitoring these actions becomes important. An analyst role ("A" in Figure 1) can coordinate organizational activities with 
different types of standardization $(3,4$, and 5) indicating a specification or programming of the contents of work processes (4). Outputs can be standardized by specifying the results of the work (5), for example, the dimensions of an e-service or the output of coordinating it. Skills (3) are standardized when the expertise required to perform work is specified beforehand [3]. Norms (3) are standardized to influence human action; as an indirect, or even subtle, form of coordination [13] (cf. organizational culture). In addition to the described hierarchical or vertical coordination in the form of direct supervision and standardization, horizontal or non-hierarchical coordination is often performed by a coordinator role reporting to top-management but with no formal authority in the areas of coordination [15].

We acknowledge some of the criticisms concerning coordination as expressed above, put forward by, e.g. Larsson [16] and Melin and Axelsson [17] implying coordination being too focused on planned activities, designed elements of organizing and material flow in organizations. Further, Adler [18] describes the importance of the temporal dimension of coordination since its mechanisms and organizational dependencies need to change over time. In response, to achieve a dynamic and flexible view of coordination, we combine the lens of coordination as mechanisms with the view of coordinating as practice described below.

\subsection{Coordination as practice}

Okhuysen and Bechky [19] describe the interdisciplinary field of coordination research as increasingly interested in the processes and practices of coordination. This enables more in-depth investigations of coordinating as an ongoing dynamic aspect of organizational activities [20]. Faraj and Xiao [21] emphasize the areas of expertise and dialogic coordination hence aspects such as the community of practice and knowledge sharing become critical to the distributed expertise needed for coordinating. Thus, coordinating as practice refers to enactment in accordance with formal mechanisms as well as an activity emerging in the absence of such mechanisms. This implies that there is not one optimal way of coordination since coordinating activities are focused on managing dependencies in organizational settings [8]. Dynamic coordination often takes place during problem-solving tasks among organizational participants [22]. In this paper, we apply the conceptual model of Jarzabkowski et al. [6] consisting of the five overlapping stages or cycles of coordinating as practice (Figure 2). Enacting disruption (1) focuses on any obstacles or disruptions of barriers forced upon coordinating activities caused by formal organizational policies and structures and orienting to absence (2) represents the attempts to organize or re-organize any coordinating activities needed by employees to be able to perform their operational work. Creating elements (3) starts when actors initiate the formation activities to facilitate the needed coordination. Elements that are further developed and refined during forming patterns (4). Stabilizing patterns (5) occurs when elements and patterns stabilize as an acknowledged practice. 


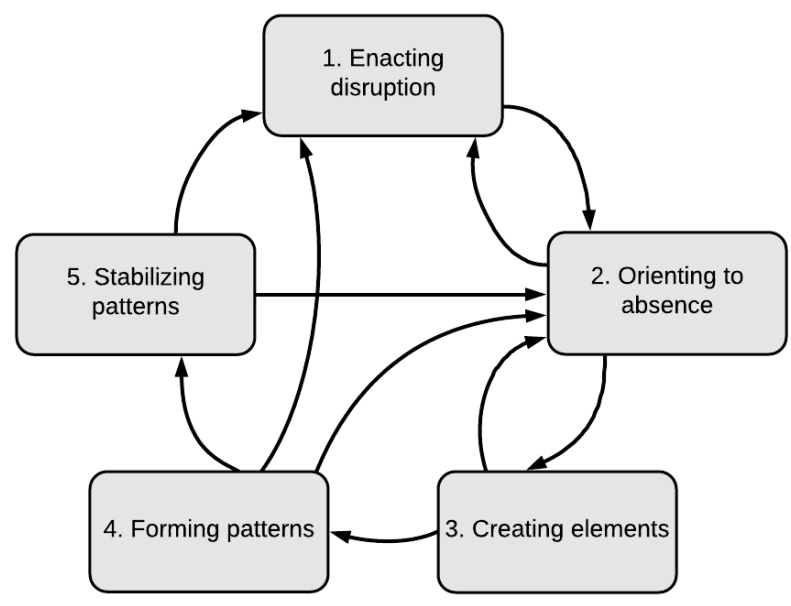

Fig. 2. Cycles of coordinating as practice [adapted from 6, p. 919]

Accepting and acknowledging these elements and patterns of coordination as appropriate ways of performing tasks occurs during the final stage of this cycle. Unlike the described formal mechanisms, this five-cycle model emphasizes aspects such as disruptions of work processes and the absence of coordination enabling us to seek relationships between the formal and informal dimensions of coordination. In previous research, we identify a lack of application of the view of coordination as practice; hence, this is the theoretical gap we address in this paper.

\subsection{Public e-services and coordination}

Using public e-services as a communication channel between citizens and government is perceived and promoted as a way of improving the efficiency and effectiveness of public sector organizations [11]. Public e-services are electronically mediated services, provided by public organizations, through which the users and the supplying organization co-create some value through the users' consumption of the service [23]. Policies, as well as citizens' needs and expectations, govern these services. There are persisting challenges associated with public e-service development such as the provision and use; service quality [24], service design [25], and uptake and use [26]. Significant challenges stem from the inherent complexity of this phenomenon. E-services refer to a process as well as an IT-artefact [23] which in turn challenges how we can understand and organize related work. Moreover, public e-services vary in complexity and type [27, 28] with different types of services putting different demands on the organization providing them. We thereby stress the need to take this complexity as well as coordination of eservices into account. Furthermore, coordination and control facilitate and increase the efficiency of delivery of services in public bureaucratic organizations [29]. Public sec- 
tor digitalization also increases the need for coordination due to higher levels of technical complexity, service complexity as well as organizational inter- and intra-dependencies. Coordination of services is therefore required to maintain high levels of quality due to the increasing number of dependencies related to areas such as services, channels, and systems [12]. There are studies in e-government inspired by formal coordination (above) for example that focused on inter-organizational e-service integration [e.g. 30]. However, the research related to e-service coordination seems to be limited with exceptions such as coordination of integrated service delivery across public organizations [30] and dependencies in multi-channel service delivery [12].

\section{Research approach and case study}

The presented research is based on a qualitative and interpretive case study [31, 32] conducted at the Swedish Transport Administration (STA) as part of a research project investigating the development and use of e-services within this agency. Conducted during 2016-2017, the overall project aimed to gain a deeper understanding of how public organizations can organize e-service development and implementation ensuring value for internal as well as external stakeholders. The STA is responsible for the long-term planning of the national transport system covering all types of traffic, as well as building, operating, and maintaining public roads and railways. The agency is located in several geographic regions in Sweden and divided into departments each responsible for development and provision of its own e-services. At the outset of this study, the STA called for one generic way to coordinate their heterogeneous and fragmented eservice landscape. We interpret this fragmentation as the result of historically weak coordination and control in this area, in combination with high levels of independence among departments within the agency.

Our qualitative data collection included two different sources. First, nine semi-structured interviews [33] were conducted from October to December 2017 with respondents from different departments. Two interviews were conducted face-to-face, with the rest conducted via telephone. Open-ended questions guided the interviews and focused on different shapes and roles of coordination. Since this study aims to investigate existing as well as emergent or even lack of coordination of public e-services, this approach enabled all performed interviews to contribute positively to the study. For reasons of space, only a selection of empirical findings are presented and analysed in this paper. Second, a hermeneutic literature review [34] was performed to increase our understanding of coordination in the form of mechanisms and emerging practices as well as coordination in a public e-service context. Therefore, during this study, the process of identifying and interpreting relevant literature was a continuous process affected by our developing knowledge of the focused research field. This study is thereby based on empirical data while using theory as a guide [32]. Data analysis was conducted iteratively during data generation, and responses were categorized, as a part of a content analysis approach [35]. Emerging categories were identified in previous research as an example of a reflexive research process [36]. To be able to model mechanisms and 
practices of coordination based on respondents' statements, the organizational and operational contexts were analysed in detail. This enabled the identification of formal as well as informal structures and activities of coordination and the lack thereof.

\section{Coordinating e-services at the STA}

Below we present the analysis of e-services within the STA, based on the two selected theoretical lenses of coordination. The aim of the first stage of analysis (section 4.1) is twofold. First, we want to categorize the area of e-service coordination through the lens of coordination as mechanisms. Second, this stage serves as a stepping-stone providing us with crucial findings to perform the next stage of analysis. The aim of the second stage of the analysis (section 4.2) is to investigate the coordinating practice indicated by areas of mutual adjustment identified during the previous stage. For the second stage, we use an excerpt of empirical data collected at the Customer Service department.

\subsection{E-service coordination mechanisms}

The E-service Catalogue is located at the external website and provides a single point of access to the majority of the e-services provided by the agency. Services range from simple web-forms to advanced forms of e-services. Without any explicit direct supervision, the Communications department was responsible for bringing together all eservices as owned and provided by different departments into a central e-service catalogue. Hence, this created a need for interdepartmental coordination across the organization. As an example of mutual adjustment, the Communications department investigated and assessed the status of all e-services as well as located responsible departments and contact persons. Another example is the Customer Service department with caseworkers assigned to the tasks of handling incoming client cases via channels such as telephone and email. We perceive caseworkers as forced to take the responsibility of forming coordination elements and patterns of their own to be able to solve the cases at hand. Public agencies, as well as other government bodies, are requested to have a precisely formulated strategy on how to transpose the benefits of modern technology into government business, i.e. public sector digitalization. We, therefore, interpret the agency's Digitalization strategy as an example of direct supervision as driven by central strategies and policies on national as well as organizational level. However, we identify a gap between policy and operational level due to challenges of translating the aims of the policy into actual benefits for local operations.

The mechanism of standardization is identified in current efforts regarding service design, the Service Forum, aimed at applying a standardized and aligned perspective and organization to assess and develop different kinds of services across the organization. The Service Forum is also identified as an example of direct supervision since we interpret this forum as an arena for increased coordination and operationalization of a service design model across the organization. However, with this forum potentially affecting processes as well as results across the organization, we have not seen any convergence between this coordination mechanism and structures and processes 
related to the internal handling of e-services within the agency. The Case Management Project is another example of an effort with distinct aims of providing coherent technical infrastructure for case handling across the organization hence, this project relates to technical standardization. Still, in its early stages, the project will require extensive and explicit coordination during its phases of design and implementation to provide the anticipated high level of standardized and automated coordination of cases. Moreover, this project will most likely have a significant impact on the internal handling of cases in turn linked to external e-services towards citizens.

\subsection{E-service coordinating practices}

We begin by expanding the scope of enacting disruption to include organizational contexts not covered by any formal mechanisms of coordination. Our interpretation of disruption marks a need for informal coordinating practices to solve the challenges at hand. The following statement describing the e-service landscape at the STA identifies this type of disruption. "From our perspective, it's very messy and complex. We wish to have a complete picture; that it should work in the same way everywhere." (Customer Service, interview). Caseworkers at the Customer Service department are struggling to handle the challenges of supporting a large number of different e-services, and the external e-service catalogue has had a rather unanticipated impact on this department regarding how client cases are forwarded internally. "Today it probably ends up at Customer Service. It's our contact number showing on the website and e-service forms, but it's just a service catalogue, really. When we receive the case, we handle it to be best of our ability. " (Customer Service, interview). The e-service catalogue serves as a single point of access and therefore, from the client's view, creates an expectation of Customer Service being a similar single point of contact. Orienting to absence frequently occurs since caseworkers regularly face challenges needing the expertise of other employees across the organization. Caseworkers start orienting by trying to locate appropriate contact points across the organization; interpreted as an investigative and time-consuming effort.

A result of being an informal act of coordination, the lack of formal support, routines and procedures also results in new challenges. "Sometimes we detect problems in eservices, so we contact the Communications department, but they do not feel they want to act on the matter and the IT department feels they do not own this case since this is a form that goes to someone else. Therefore, we end up being caught in the middle. We identify problems that arise, but nobody wants to take responsibility. " (Customer Service, interview). Instead of finding the appropriate contact point to report and solve these problems, different departments are engaged in negotiations about what party is responsible for a particular e-service. One assumption is that it would be in the Customer Service's self-interest to try to develop a higher level and more formal way of coordinating practice shared among caseworkers. However, findings point out the challenges of creating these more structured elements. "So the biggest challenge is to keep track of what e-services are available and which one you should refer to and what to do with the different types of questions we receive" (Customer Service, interview). 
Thereby, at Customer Service, we identify the cycle of creating elements as caseworkers establish the needed forms of coordination but so far, we have not been able to find any indications of these practices reaching beyond this particular cycle of creating elements. The cycles of forming and stabilizing patterns do not seem to apply in this empirical context. Instead, existing patterns seem to prescribe that the coordinating practice needs to be formed and re-formed on a case-by-case basis. "We have no list at the office showing contact persons for each e-service. We simply make contact with someone within the organization and investigate further. A lot of our work is done in this manner." (Customer Service, interview).

\section{Discussion}

Our study shows the presence of the two suggested forms of coordination from previous research within the STA; as planned mechanisms and as emerging practices in daily work. The agency applies different types of direct supervision and standardization in their efforts to formalize and anticipate actions [2-4]. We motivate this by how eservices are presented on the external website (E-Service Catalogue) and how cases are internally managed with the support from the new technical infrastructure (Case Management Project) potentially increasing internal efficiency as well as the external availability [e.g. 10,11]. During the first stage of analysis, we identify mutual adjustment existing on the operative level [3] in contexts such as the E-service Catalogue and the caseworkers' handling of client cases in the Customer Service department. This coordination takes place in areas with very limited, or total absence of, direct supervision and standardization with a clear aim of problem-solving [22]. Coordinating activities thereby include characterizing dependencies and identifying potential coordination activities [8] as well as locating the needed expertise [21] across the organization. In contrast to the previously described analyst role in formal mechanisms acting upon coordination in the form of standardization, we perceive caseworkers as operative level coordination analysts or informal coordinators supporting activities based on mutual agreements [c.f. 3]. These activities are efforts to mitigate the effects of the absence or lack of formal coordination mechanisms.

To develop a better understanding of these mutual adjustments as areas of emerging coordinating practices, we use an empirical subset of data as the basis of stage two of the analysis. During the first cycle of enacting disruption, caseworkers describe the fragmented and heterogeneous e-service landscape as having a significant impact on their daily work preventing them from having a clear picture of the internal e-services linked to the external e-service catalogue. To solve client cases, caseworkers need the distributed knowledge from different departments across the organization such as Communications and IT, as well as specific departments in their roles as e-service providers. However, there is a lack of an internal overview of structures and dependencies such as internal case handling systems linked to external e-services. This indicates a lack of understanding of the different roles of e-services; as artefacts, as well as interlinked processes [23]. We also interpret this as a result of the complexity and fragmentation 
in the organization [12] combined with a lack of knowledge and support regarding organizational interdependencies behind these e-services. Thereby, caseworkers need to bridge this gap on a daily and operational basis, a gap to which we, in this context, assign the concept of disruption.

During the cycle of orienting to absences, caseworkers start to assess and investigate further the situation in their efforts to deconstruct the problem at hand into manageable elements. Since cases regarding e-services do not follow any organizational structures or boundaries [12], caseworkers try to identify dependencies to be able to perform activities of horizontal coordination in each case. Since there is no clear picture of the eservice landscape, they usually approach an actor deemed suitable as the first contact for the continued investigation. When clients report problems of a more general nature on the website, caseworkers approach internal support functions such as the Communications and IT departments. It is therefore interesting to learn that these support functions seem to avoid taking any responsibility and act upon such cases. This can be interpreted as another indication of a lack of knowledge and understanding of the eservice landscape as well as a consequence of the caseworkers' lack of authority in their roles as coordinators [15].

When creating elements, caseworkers depend on their individual experiences and tacit knowledge of dependencies linking the external e-service to internal department functions to facilitate the creation of the needed coordination in each case. This is also an example of the agency's lack of acknowledgment and support of caseworkers at Customer Service in their roles as informal coordinators. Acting without any support of formal coordination, such as direct supervision [3], this prevents the development of any stabilized and formalized patterns to support further coordinating activities. Without any formal acknowledgment and support, coordinating practices take place, but in a significantly un-coordinated way. From our point of view, caseworkers at Customer Service have a vital role as informal coordinators; a role that needs be both formally acknowledged and supported by the organization.

The main findings of this study are the following three: First, by addressing RQ1, we confirm that activities related to internal structures and processes related to e-services are coordinated in several ways ranging from direct supervision and standardization to mutual adjustment and emerging coordinating practices. Findings show several informal coordination activities performed without the informal coordinator, e.g. caseworkers at Customer Service department, being aware of underlying interdependencies between different structures and processes. This results in a disability to support other coordinating activities, as well preventing any forming and stabilizing patterns of recurring coordinating activities [6]. Second, by answering RQ2, we describe and analyse the identified contexts and occurrences of coordination where the first analytical stage focuses on coordination mechanisms thus guiding the second stage where a deeper understanding of coordinating as practice is developed. Hence, this approach enables us to uncover and investigate the complexity and interdependencies of coordinating mechanisms as well as coordinating practice in daily activities. Third, as a result of this study, we put forth the need to expand existing formal oriented views of coordination, such as fixed sets of coordination mechanisms, with perspectives that can potentially identify and capture emerging informal dimensions of coordinating. By addressing RQ3, we 
thereby agree with scholars such as Malone and Crowston [8] and Jarzabkowski et al. [6] emphasizing a balanced handling of organizational actions and a need to consider and understand coordination as mechanisms as well as practice.

\section{Concluding remarks and future research}

In this study, we apply two views on coordination to empirical data to further investigate and analyse formal and informal dimensions of coordination in a fragmented and heterogeneous public agency e-service context. Although the agency was seeking one generic way or a 'one-size-fits-all' approach, e.g. a framework or best practice, to coordinate internal e-services, our findings point towards the need of also considering more balanced, dynamic and flexible views of coordination in this area. By applying an emergent view on coordination, we also agree with Okhuysen and Bechky [19] stating that "coordination is an ongoing accomplishment in organizations." (p. 493). In this paper we, therefore, conclude that the e-services to be coordinated do not depend on technical dimensions of the artefacts, formal structures and mechanisms alone; they are also intertwined with organizational and social constructs inherent to the accepted working practices and informal relationships and dependencies among participating actors [c.f. 8, 9]. The implications of this study assumes a need to look beyond pre-formulated fixed-set view and instead increase our sensitivity to the emerging dynamics of coordination in public sector digitalization. As our final conclusion in this paper, we argue that being too focused on a single or formal views of coordination will delimit the organization from a broader in-depth understanding of the informal dimensions of coordinating as emerging activities.

We put forth the added value of combining approaches of coordination that cover planned as well as emerging forms of coordination, in research as well as in practice. This combination of views is in agreement with Jarzabkowski et al. [6] emphasizing the need for looking beyond fixed and ready to be used views of coordination. We are fully aware that various governance approaches, such as IT-governance frameworks, can address challenges of internal coordination of public e-services. However, such frameworks focus on formal management in terms coordination and direction of ITrelated decisions. As a contrast, we stress the importance of understanding the informal dimension of coordinating as practice on the organizational level. We argue that this will improve the understanding of the objects of coordination (e-services), as well as its organizational context. However, emergent coordinating activities can be challenging to identify while placing formal coordination in the foreground. There is also an inherent risk of bias towards the anticipated outcome of coordination as known a priori.

Regarding the limitations of this study, it could be argued that it was performed during a limited timeframe with a rather small sample size in one single organization hence, the level of generalizability should be considered low. However, as stated in the introduction, given our study's qualitative and interpretive character, our aim is not to provide any statistically generalizable results, but rather put forward the need of a better understanding of different shapes and roles of coordination by presenting and applying 
one potential approach where formal mechanisms as well as informal practices of coordination can be potentially integrated, an provide an illustrative case with analytical generalizability. Since this is our first attempt bringing these two theoretical lenses of coordination mechanisms and coordinating practices together, we seek to further develop our understanding of the complexity and interwoven character of technical, organizational and social dimensions of internal coordination, in an e-government context in general and in an e-service context in particular. A particular area of interest in future research is to further develop the suggested approach of combining and mutually adjusting or coordinating, formal coordination and informal coordinating activities for an increased understanding of the different shapes and forms of coordination.

\section{Acknowledgements}

This work was supported by the Swedish Transport Administration.

\section{References}

1. Weick, K.: The Social Psychology of Organizing. 2nd edn. McGraw-Hill (1979).

2. March, J.G., Simon, H.A.: Organizations. Wiley, New York (1958).

3. Mintzberg, H.: Structure in fives: designing effective organizations. Prentice Hall, New Jersey (1983).

4. Thompson, J.D.: Organizations in action: Social science bases of administrative theory. Transaction publishers (1967).

5. Thomas, G., Botha, R.A., van Greunen, D.: Understanding the problem of coordination in a large scale distributed environment from a service lens view - Towards the South African public sector e-Administration criteria for coordination support. Government Information Quarterly 32(4), 526-538 (2015).

6. Jarzabkowski, P.A., Lê, J.K., Feldman, M.S.: Toward a theory of coordinating: Creating coordinating mechanisms in practice. Organization Science 23(4), 907-927 (2012).

7. Melin, U.: The enterprise system as a part of an organization's administrative paradox. Journal of Enterprise Information Management 23(2), 181-200 (2010).

8. Malone, T.W., Crowston, K.: The interdisciplinary study of coordination. ACM Computing Surveys (CSUR) 26(1), 87-119 (1994).

9. Orlikowski, W.J., Scott, S.V.: 10 Sociomateriality: Challenging the Separation of Technology, Work and Organization. The academy of management annals 2(1), 433-474 (2008).

10. Axelsson, K., Melin, U., Lindgren, I.: Public e-services for agency efficiency and citizen benefit-Findings from a stakeholder centered analysis. Government Information Quarterly 30(1), 10-22 (2013).

11. Bertot, J., Estevez, E., Janowski, T.: Universal and contextualized public services: Digital public service innovation framework. Government Information Quarterly 33(2), 211-222 (2016).

12. Klievink, B., Janssen, M.: Coordinating e-government service delivery. 11th Annual International Conference on Digital Government Research (dg.o 2010), pp. 209-216. Digital Government Society of North America, Puebla, Mexico (2010). 
13. Mintzberg, H.: Five Ps for Strategy. In: Mintzberg, H., Quinn, J.B., Ghoshal, S. (eds.) The Strategy Process. Prentice-Hall, New Jersey (1998).

14. Van de Ven, A.H., Delbecq, A.L., Koenig Jr, R.: Determinants of coordination modes within organizations. American sociological review 322-338 (1976).

15. Lawrence, P.R., Lorsch, J.W.: Differentiation and Integration in Complex Organizations. Administrative Science Quarterly 12(1), 1-47 (1967).

16. Larsson, R.: Coordination of Action in Mergers and Acquisitions - Interpretive and Systems Approaches towards Synergy. vol. PhD Thesis. Lund University, Sweden (1990).

17. Melin, U., Axelsson, K.: Understanding Organizational Coordination and Information Systems-Mintzberg's Coordination Mechanisms Revisited and Evaluated. Proceedings of the 13th European Conference on Information Systems, pp. 1634-1644. (2005).

18. Adler, P.S.: Interdepartmental interdependence and coordination: The case of the design/manufacturing interface. Organization science 6(2), 147-167 (1995).

19. Okhuysen, G., Bechky, B.: Coordination in organizations: An integrative perspective. The Academy of Management Annals 3(1), 463-502 (2009).

20. Feldman, M.S., Orlikowski, W.J.: Theorizing practice and practicing theory. Organization science 22(5), 1240-1253 (2011).

21. Faraj, S., Xiao, Y.: Coordination in fast-response organizations. Management science 52(8), 1155-1169 (2006).

22. Ching, C., Holsapple, C.W., Whinston, A.B.: Reputation, learning, and coordination in distributed decision-making contexts. Organization Science 3(2), 275-297 (1992).

23. Lindgren, I., Jansson, G.: Electronic services in the public sector: A conceptual framework. Government Information Quarterly 30(2), 163-172 (2013).

24. Jacobsen, D.I.: Adopting and Refining e-services - the Role of Organization Size. Public Organization Review 1-13 (2016).

25. Goldkuhl, G.: What does it mean to serve the citizen in e-services?-Towards a practical theory founded in socio-instrumental pragmatism. International Journal of Public Information Systems 3(3), 135-159 (2007).

26. Angelopoulos, S., Kitsios, F., Kofakis, P., Papadopoulos, T.: Emerging barriers in egovernment implementation. Electronic Government. EGOV 2010, Lecture Notes in Computer Science, vol 6228, pp. 216-225. Springer, Heidelberg (2010).

27. Jansen, A., Ølnes, S.: The nature of public e-services and their quality dimensions. Government Information Quarterly 33(4), 647-657 (2016).

28. Lindgren, I., Melin, U.: Time to Refuel the Conceptual Discussion on Public e-ServicesRevisiting How e-Services Are Manifested in Practice. Electronic Government. EGOV 2017, Lecture Notes in Computer Science, vol 10428., pp. 92-101. Springer, Cham, (2017).

29. Cordella, A., Tempini, N.: E-government and organizational change: Reappraising the role of ICT and bureaucracy in public service delivery. Government Information Quarterly 32(3), 279-286 (2015).

30. Os, G.v.: The challenge of coordination: Coordinating integrated electronic service delivery in Denmark and the Netherlands. Information Polity 16(1), 51-61 (2011).

31. Myers, M.D.: Qualitative Research in Business \& Management. SAGE Publications, London (2009)

32. Walsham, G.: Interpretive case studies in IS research: nature and method. European Journal of information systems 4(2), 74-81 (1995).

33. Myers, M.D., Newman, M.: The qualitative interview in IS research: Examining the craft. Information and Organization 17(1), 2-26 (2007). 
34. Boell, S.K., Cecez-Kecmanovic, D.: A hermeneutic approach for conducting literature reviews and literature searches. Communications of the Association for Information Systems 34(1), 257-286 (2014).

35. Krippendorff, K.: Content analysis: An introduction to its methodology. 2nd edn. Sage Publications, Thousand Oaks (2004).

36. Alvesson, M., Sköldberg, K.: Reflexive methodology: New vistas for qualitative research. Sage, London (2009). 